\title{
Post-Ganglionic Horner's Syndrome: An Unusual Presentation of Non-Hodgkin Lymphoma
}

\author{
Lucilene Silva Ruiz e Resende ${ }^{a} \quad$ Rafael Dezen Gaiolla ${ }^{a}$

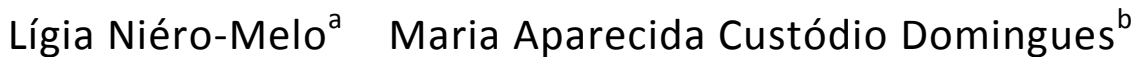 \\ Luiz Antônio de Lima Resende ${ }^{c}$ \\ ${ }^{a}$ Hematology Service, Internal Medicine Department, Departments of ${ }^{b}$ Pathology and \\ ${ }^{\mathrm{c}}$ Neurology, Psychology and Psychiatry, Botucatu Medical School, São Paulo State University, \\ Botucatu, Brazil
}

\section{Key Words}

Non-Hodgkin lymphoma · Horner's syndrome - Cervical lymphadenopathy · Third-order neuron pathway · Neoplasia

\begin{abstract}
In this paper, we present the rare case of a patient with cervical lymphadenopathy diagnosed as a T-cell-rich B-cell non-Hodgkin lymphoma that manifested Horner's syndrome due to a post-ganglionic sympathetic neuron lesion caused by the tumor.
\end{abstract}

\section{Introduction}

Sympathetic innervation of the eye is a third-order neuron pathway which emerges from the hypothalamus and runs along a well-known route before reaching the eye [13]. The third-order neuron is located in the superior cervical ganglion dividing itself into two branches which innervate the Müller's muscle of the eyelids, lacrimal gland, iris dilator muscle, facial sweat glands and the small skin vessels [1-3]. Horner's syndrome, also called oculosympathetic paresis, results from any lesion that interrupts the sympathetic neuronal pathway from the hypothalamus to the eye. It manifests ipsilaterally to the lesion, consisting mainly of miosis, slight ptosis and enophthalmos, but can present other findings [1-3]. Horner's syndrome can be caused by many benign and malignant conditions [1-4]. Neoplasia is the most common cause and accounts for $35-60 \%$ of all cases [2-4]. Non-Hodgkin lymphomas, however, are uncommonly related to this syndrome. The purpose of this paper is to present the case of a woman with a left cervical mass corresponding to a T-cell-rich B-cell non-Hodgkin lymphoma that manifested Horner's syndrome due to a sympathetic third-order neuron lesion at diagnosis. To our knowledge, this is the first case of Horner's syndrome secondary to a 
lesion in the post-ganglionic level of the sympathetic pathway in a non-Hodgkin lymphoma.

\section{Case Report}

A 35-year-old woman was admitted with a cervical lymphadenopathy which had progressively grown over the last 3 months. It consisted of a coalescent group of hard lymph nodes that infiltrated adjacent tissues and skin, posteriorly located on the left side of the neck (fig. 1a). Simultaneously she presented ipsilateral miosis, slight superior eyelid ptosis, and enophthalmos typical for Horner's syndrome (fig. 1b). She did not present hemifacial anhydrosis or flushing. The ocular phenylephrine $1 \%$-test revealed minimal dilatation in the normal right pupil and pronounced dilatation in the left affected pupil (fig. 1c). CT scan of the neck confirmed a lymphadenopathy that occupied the carotid and paravertebral spaces. Thoracic CT scan did not show any tumor in the mediastine or left lung apex. Cervical tumor biopsy revealed a T-cell-rich B-cell non-Hodgkin lymphoma

[immunohistochemistry: 100\% large lymphocytes CD20(+); 40\% large lymphocytes CD45(+); background lymphocytes CD3(+); CD15(-); CD30(-); ALK-1(-)]. As liver and bone marrow were both compromised but without B symptoms, the tumor was classified as stage IVA by the Ann Arbor Staging System, and she was treated with 6 cycles of R-CHOP. Until present, the patient has been receiving salvage chemotherapy with ifosfamide, carboplatin and etoposide due to a relapse affecting the lungs occurring after 2 years of complete clinical remission. As soon as she reaches the second remission, she will undergo an autologous bone marrow transplant.

\section{Discussion}

We found a small number of papers citing or describing Horner's syndrome related to non-Hodgkin lymphomas [5-9]. They were reported as tumors that primarily affected the intramedullary spinal cord (C3-C6) [9], lung apex (Pancoast's syndrome presentation) [6, 7], the thyroid gland [5], or which were spread throughout the patient's body including a supraclavicular lymphadenopathy [8]. These published cases, however, seem to be the result of sympathetic neuronal pathway interruption in the first- [9] or second-order neuron pathways [6-8]. In 1958, Giles and Henderson [4] cited a case of malignant lymphoblastoma that caused Horner's syndrome in one of their study patients. This tumor could correspond to a non-Hodgkin lymphoma, but the sympathetic lesion level was not specified [4]. According to Danesh-Meyer et al. [10], the phenylephrine test finding observed in our patient locates the lesion in the thirdorder neuron level (post-ganglionic). This can be explained by the principle of denervation supersensitivity which occurs in the affected side. As the patient did not show hemifacial anhydrosis or flushing, it seems that the lesion specifically affected the third-order neural branch along the internal carotid artery [3].

It is well-known that neck lymphadenopathy from any cause can result in Horner's syndrome [3]. Nonetheless, our paper illustrates a rare presentation of non-Hodgkin lymphoma, mainly because it seems to be the first well-documented case of a thirdorder sympathetic neuron lesion caused by this kind of malignancy. 



Fig. 1. a Tumor mass consisting of coalescent hard lymph nodes that have infiltrated adjacent tissues and skin, posteriorly located on the left side of the neck. b Myosis, slight upper eyelid ptosis, and enophthalmos characterizing Horner's syndrome in the left eye. c The phenylephrine $1 \%$ test shows bilateral mydriasis which is more pronounced in the affected left pupil than in the non-affected right pupil. The test results locate the lesion in the third-order neuron level (post-ganglionic). 


\section{References}

1 Wilhelm H, Ochsner H, Kopycziok E, Trauzettel-Klosinski S, Schiefer U, Zrenner E: Horner's syndrome: a retrospective analysis of 90 cases and recommendations for clinical handling. German J Ophthalmol 1992;1:96-102.

-2 Bell RL, Atweh N, Ivy ME, Possenti P: Traumatic and iatrogenic Horner syndrome: case reports and review of the literature. J Trauma 2001;51:400-404.

-3 Patel S, Ilsen PF: Acquired Horner's syndrome: clinical review. Optometry 2003;74:245-256.

-4 Giles CL, Henderson JW: Horner's syndrome: an analysis of 216 cases. Am J Ophthalmol 1958;46:289296.

-5 Billie JD, Wetzel WJ, Suen JY: Thyroid lymphoma with adjacent nerve paralysis. Arch Otolaryngol 1982;108:517-519.

6 Dolganova A, Moreira AL, Barra M, Moreira JS: Síndrome de Pancoast causada por linfoma. J Pneumol 2000;26:145-148.

7 Rao RD, Robins HI: Non-Hodgkin tumor and Pancoast's syndrome. Oncol Reports 2001;8:165-166.

$\checkmark 8$ Nissenbaum M, Kaban LB, Troulis MJ: Toothache, paresthesia, and Horner syndrome: an unusual presentation of disseminated Burkitt's lymphoma. J Oral Maxillofac 2007;1395-1401.

\$9 Peltier J, Cretu I, Fichten A, Toussaint P, Desenclos C, Le Gars D: Lymphome primitive intramédullaire. À propos d'un cas. Neurochirurgie 2007;53:375-378.

10 Danesh-Meyer HV, Savino P, Sergolt R: The correlation of phenylephrine $1 \%$ with hydroxyamphetamine 1\% in Horner's syndrome. Br J Ophthalmol 2004;88:592-593. 